Supplement of Nat. Hazards Earth Syst. Sci., 17, 1159-1175, 2017

https://doi.org/10.5194/nhess-17-1159-2017-supplement

(c) Author(s) 2017. This work is distributed under

the Creative Commons Attribution 3.0 License.

(c) (1)

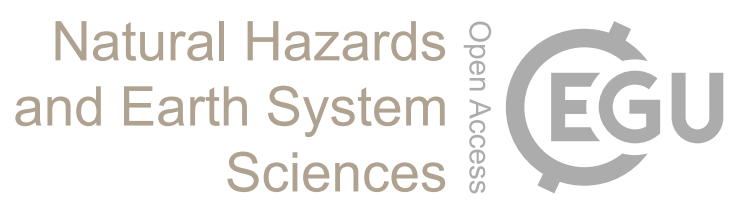

Supplement of

\title{
Prediction of the area affected by earthquake-induced landsliding based on seismological parameters
}

Odin Marc et al.

Correspondence to: Odin Marc (odin.marc@unistra.fr)

The copyright of individual parts of the supplement might differ from the CC BY 3.0 License. 

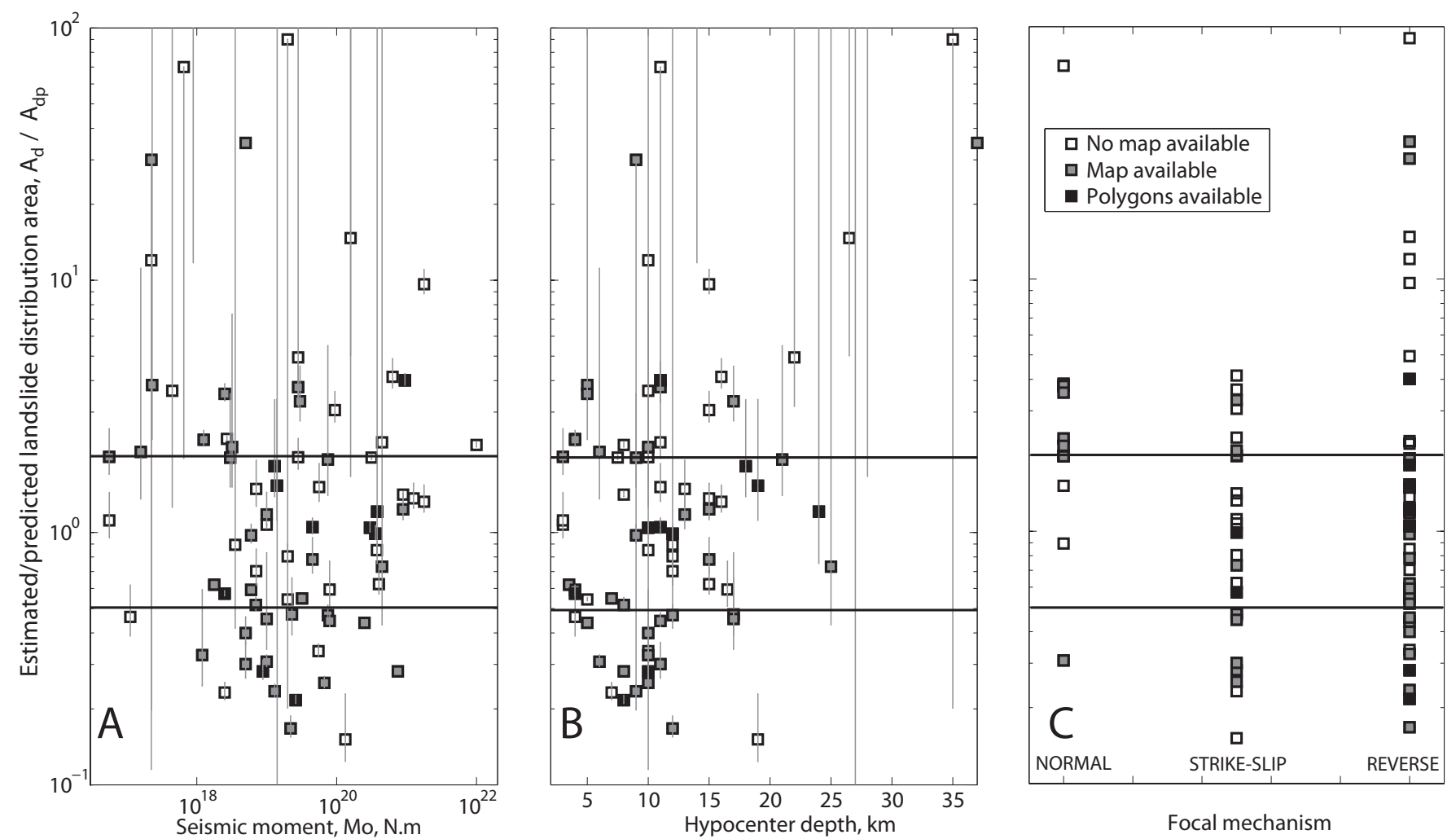

Supplementary Figure 1. Landslide distribution area residuals (Estimated area over predicted area), plotted against seismic moment (A), hypocenter depth (B), and focal mechanism (C). Horizontal black lines delimit cases where the residuals are within a factor of 2 of a correct prediction (i.e., residual $=1$ ). Grey vertical error bars indicates the variability in model prediction and residuals when varying the emission depth $R_{0}$ within $25 \%$ of the hypocenter depth. For visibility these uncertainty ranges are not shown in (C). 


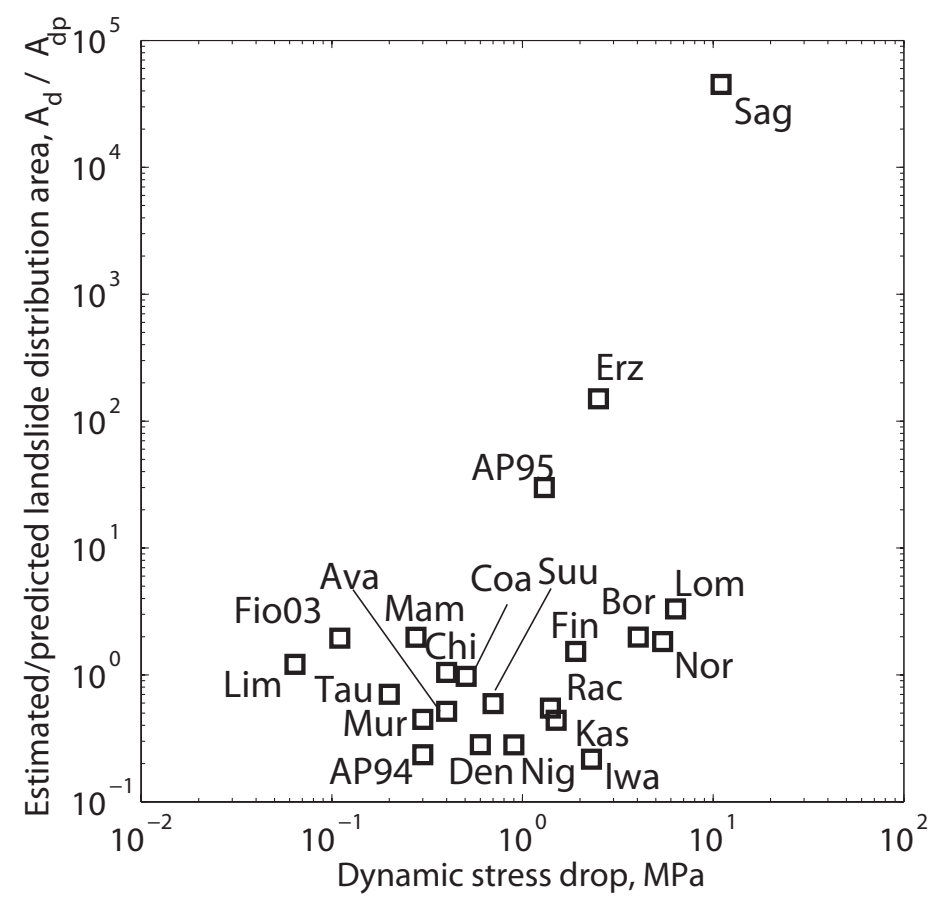

Supplementary Figure 2. Landslide distribution area residuals (Estimated area over predicted area), plotted against earthquake dynamic stress drop. The three letters name codes are defined in Table 1. $1 \mathrm{MPa}$ is a typical median stress drops value in large earthquake catalogue. 